cantly ( $p<0.05)$. Acrophases were all between 15:30 and $17: 45$, VE manifesting the strongest amplitude. A circadian oscillation was observed in $\mathrm{VO}_{2}$ at $150 \mathrm{~W}$ when values were uncorrected for body weight and resting levels, the acrophase occurring at 14:40 $(p<0.05)$. Gross efficiency was $18( \pm S D=0.8) \%$ and 20.9 ( $\pm \mathrm{SD}=0.7) \%$, net efficiency was $24.5( \pm \mathrm{SD}=0.5$ ) and 25.2 ( $\pm \mathrm{SD}=0.2) \%$ at the light and heavier loads while delta efficiency was $26( \pm S D=2.2) \%$. None of the efficiency calculations varied with time of day, the significant increase in gross efficiency with work increment being a computational artefact.

$\mathrm{VO}_{2}$ responses attained steady-rate in the second minute of each load irrespective of time of day. Ventilation values at each load failed to stabilise until the fourth minute, this adaptation rate being independent of time of day. The circadian rhythm in VE persisted in phase and amplitude at both loads, delta values over rest being similar for the 6 time points. The ventilatory equivalent ( $\left.\mathrm{VE} / \mathrm{NO}_{2}\right)$ during steady-rate was 22.9 $( \pm S D=1.3)$ : the value was unaffected by the work intensities used but varied with time of day at each load $(p<0.05)$.

\section{LIGHT EXERCISE}

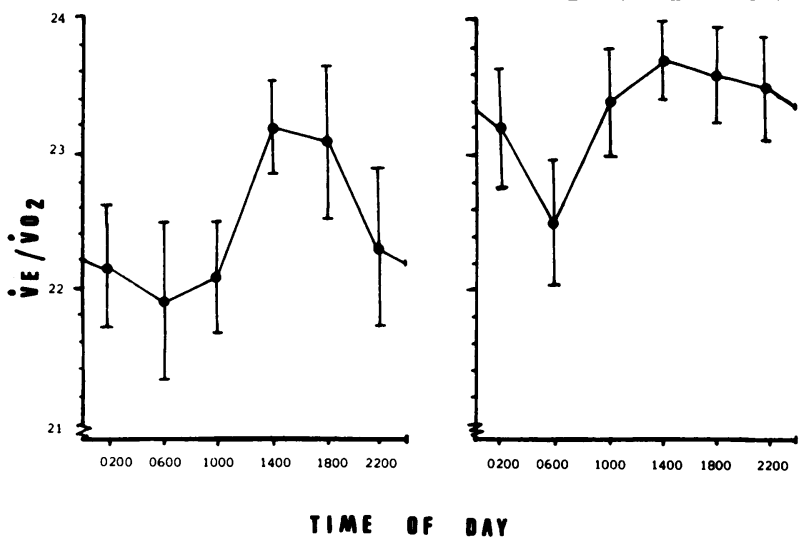

Fig. 1. Ventilatory equivalent for 6 times of day at light and medium intensity exercise.

Results suggest that the periodicity in ventilation is partially independent of the oscillator linking body temperature and metabolic rate. Its persistence in submaximal exercise has only minor repercussions for cellular respiration. It is concluded that circadian rhythms in $\mathrm{VO}_{2}$ are relatively unimportant in affecting the rate and level of adaptation to moderate work loads: the more robust VE cycle contributes to the greater discomfort associated with nocturnal exercise without any al teration in muscular efficiency.

\section{TABLE I}

Mean percentage of 5 th minute value for each minute at light and medium exercise intensity.

\begin{tabular}{lcccc} 
& \multicolumn{2}{c}{ Light Exercise } & \multicolumn{2}{c}{ Medium } \\
& $\mathrm{VO}_{2}$ & $\mathrm{VE}$ & $\mathrm{VO}_{2}$ & Exercise \\
& & & & \\
1st minute & 73.1 & 76.4 & 81.1 & 79.2 \\
2nd minute & 101.9 & 93.1 & 98.9 & 95.9 \\
3rd minute & 100.8 & 96.2 & 98.9 & 97.8 \\
4th minute & 99.3 & 98.2 & 98.7 & 98.5
\end{tabular}

\section{References}

Donovan, C. M. and Brooks, G. A., 1977 "Muscular efficiency during steady-rate exercise. II. Effects of walking speed and work rate." J.Appl.Physiol. 43: 431-435.

Minors, D. G. and Waterhouse, J. M., 1981. Circadian rhythms and the human. John Wright: Bristol.

\section{ESTIMATION OF TOTAL BODY FAT IN RUGBY UNION FORWARDS FROM MEASUREMENTS OF HUMAN BODY DENSITY AND SUBCUTANEOUS TISSUE THICKNESSES \\ W. Bell \\ Dept. of Physical Education, Institute of Higher Education, Cardiff}

The tissue composition of the body is an important characteristic of the practicing athlete and games player. In the United Kingdom there are a number of suitable equations for the estimation of TBF in normal individuals, but because of the differences between athletic and non-athletic groups these equations are seldom appropriate for sportsmen and women. It is desirable that specific equations be formulated for particular sporting groups. The present study, therefore, provides prediction equations to estimate TBF in rugby union forwards.

Measurements of human body density were determined by hydrostatic weighing. Ten measurements were taken, the mean of the last three trials being used as the final underwater weight. A correction was made for residual volume using the closed circuit three-breath nitrogen dilution technique. Four skinfolds were taken on the left hand side of the body at the biceps, triceps, subscapular and suprailiac sites. Linear regression equations were determined to estimate body density from single skinfolds and from the sum of the four skinfold measurements.

Body density was used as the dependent variable and skinfold thickness as the independent variable. Because 
skinfold thicknesses are known to be skewed calculations were repeated using the logarithmic transformation of both individual and summed skinfolds.

Coefficients of correlation between body density and the logarithmic transformation of the individual and summed skinfolds were uniformly higher $(-0.64$ to -0.85 ) than those between the raw skinfolds and body density $(-0.61$ to -0.82$)$. The best single predictor was the logarithm of the suprailiac skinfold, the worst triceps. The regression equation for the logarithm of the sum of the four skinfolds $(-0.83)$ was $Y=1.1751-$ $0.0651 X$, where $Y$ is body density and $X$ the logarithm of the sum of four skinfolds. The standard error of estimate was 0.0048 units.

It is concluded that the above equation will provide a satisfactory estimate of TBF in rugby union forwards.

\section{References}

Bell, W., 1980. J.Sports Med.Phys.Fitness 20 (4): 447-451.

Durnin, J. V. G. A. and Womersley, J., 1974. Brit.J. Nut. 32: 77-97. 